\title{
EL CORREGIDOR Y LA CO-ADMINISTRACION MUNICIPAL
}

I.-El Corregidor forma parte del Concejo Municipal, y hasta tal extremo es elemento esencial del mismo que, como dice Castillo de Bovadilla (1), "en lo que no concurre la justicia, no se puede llamar ciudad, como quiera que el Corregidor es la cabeça, y los Regidores son los miembros del cuerpo del Ayuntamiento; y así en las provisiones reales que se dirigen a los Regimientos se dice: Al Consejo, justicia y Regimiento, etc..." Las Ordenanzas municipales de San Felipe determinan concretamente que el Ayuntamiento se compone "del Corregidor, del Alférez Mayor, de doce Regidores y del Alguacil mayor, que son los que en él tienen únicamente voz y voto" (2); y que no puede celebrarse sesión válida sin la presencia de dicho Corregidor, o sin que autorice sus sustitución (3). Esto puede justificarse, además, con texto, legales, entre los cuales destaca la Ley II, Título I, Libro VII de la Recopilación, que recogiendo varias disposiciones del siglo XV hace constar que "... en los negocios de los tales Regimientos no se entremetan otros, salvo la Justicia y Regidores..."

Ahora bien, sería equivocado suponer una fusión absoluta entre los componentes del Concejo, una paridad en la situación del representante del poder real y de los miembros perpetuos del cabildo. Se observa invariablemente que en todos los documentos de la época, cómo hace notar Castillo de Bovadilla, no basta mencionar el Regimiento colectivamente para nombrar al mismo, sino que precisa hacer referencia, por separado, a cada uno de los elementos que lo constituyen-Justicia y Regidores-, los cuales permanecen en su seno perfectamente diferenciados por sus atribuciones y por los distintos criterios en que inspiran su actuación. Ello determina, en la dinámica municipal, la presencia de dos fuerzas paralelas, que contribuyen, en proporciones diversas, a la administración del territorio jurisdiccional del Ayuntamiento.

Como ya hemos apuntado, hay que tener muy en cuenta que es bien

(1) Castillo de Bovadilla: "Política para Corregidores y señores de Vasallos". Amberes, 1750. vol. II, págs. 161 y 162.

(2) Ordenanza II del Capitulo I.

(3) Ordenanza IV del Capitulo I. 
distinto el sistema establecido por las disposiciones legales en vigor del que resulta de hecho como consecuencia de la intervención de varios factores, los cuales, mediante una lenta acción consuetudinaria, llegan a transformar radicalmente el viejo régimen de predominio concejil, hasta alcanzar la definitiva función prepoderante el representante directo de la autoridad real. Originariamente, la agrupación de los regidores lo es todo. Son ellos solos quienes sustituyen, plenamente, a la Asamblea popular del primitivo Concejo abierto, investidos de todos los poderes del Gobierno local (1). Cuando llega el Corregidor a su seno, encuentra ese estado de cosas y teóricamente lo mantiene. Así pues, su actuación en el cabildo parece limitarse a una simple función presidencial: el Regimiento administra; el Corregidor, preside.

Esto es lo que se deduce de la letra de la ley y de los preceptos de las Ordenanzas de los pueblos. Ahora bien, la realidad es muy otra, como habremos de comprobar seguidamente. Sea como fuere, la ficción legal subsiste en todo momento y los tratadistas la recogen en los mismos tiempos en que el sistema del Corregidor alcanza su máxima intensidad y predominio. Veamos cómo se expresa Santayana Bustillo: "El Gobierno de los pueblos-dice este alltor (2) - , por Derecho natural, pertenece a los pueblos mismos. De éstos se derivó a los Magistrados y a los Príncipes... En nuestra España toda la potestad civil reside en su Rey, en quien la transfirieron los pueblos desde el origen de esta Monarquía. Mas reservándose sus Príncipes la Suprema Potestad, han dexado a los Pueblos el Govierno Político de sí mismos. Este reside oy en los Ayuntamientos y Concejos, cuyos sujetos, que les componen, o nombra el Rey - los mismos Pueblos, que no pudiendo governarse por todos sus individuos, la necesidad misma obliga a deputar ciertas personas para el Govierno. Pertenece, pues, al Govierno Político y económico de los Pueblos a los Ayuntamientos o Concejos dellos..."

Por ello tócanos examinar ahora aquellas funciones del Corregidor estrictamente ortodoxas. De acuerdo con las mismas este Magistrado, en sus relaciones con el Concejo, según hace constar Castillo de Bovadilla (3), "sólo preside y asiste para autorizar, oyr y executar los acuerdos del". Vamos a examinar, seguidamente, estos particulares.

A) Funciones presidenciales.-El Capítulo III de la tan repetida obra de Castillo de Bovadilla, resume las facultades presidenciales del Corregidor. Según él mismo, este Magistrado convoca al Cabilảo, impide que asistan a sus reuniones quienes no tengan derecho a ello (4) ; dirige las discusiones; impidiendo toda d l.eicion de! orden de las mismas, pudiendo expulsar y prender. a los Regidores

(1) La carta de Alfonso XI a Burgos instituyendo las Regidurias perpetuas dice asi: "Otrosi mandamos que aian el poder-los Regidores-para ver e ordenar todas las cosas e cada una dellas que el conceio faria e ordenaria, slendo en uno ayuntados".

(2) Santayana Bustillo (L.): "Gobierno politico de los pueblos de España y el Corregidor, Alcalde y Juez de ellos". Zaragoza, 1742.

(3) Castillo de Fovadilla, ob. cit.; tomo II, pág. 160.

(4) Leyes I y II, Título I, libro VII de la Recopilación. 
que lo perturben; ordena las votaciones, dirime los empates con voto de calidad y concede licencias a los Regidores para que puedan dejar de acudir a las reuniones capitulares, sancionando las faltas de asistencia no justificadas.

Las Ordenanzas de San Felipe resumen perfectamente esta actuación presidencia del Corregidor, tal como la entendía la legalidad vigente en el período ds mayor preponderancia de la institución. "En todos los negocios del cabildo-se hace constar en las mismas (1) - deve tener y tiene el Corregidor la voz para proponer lo que tenga por conveniente; advertir lo que se ofrezca en las propuestas, y votos que hagan los Capitulares; proveer los memoriales que se presenten; dar cumplimiento a los reales despachos y órdenes, responder por el Ayuntamiento a los que se admitan y cortejen en él; nombrar los comisarios extraordinarios que se ofrezcan..., pues estos actos son propios de la jurisdicción y preeminencias del Corregidor, a quien corresponden, como Presidente y cabeza del Ayuntamiento". Añadiendo en otro lugar las propias Ordenanzas (2) que "no permitirá el Corregidor-en las sesiones capitulares-disputas, ni alteraciones... y si en esto notase algún exceso... lo procurará atajar; y no moderándose-los Regidores-le mandará salir, y que se retire a su casa, o que quede arrestado en la Capitular, y procederá a lo que corresponda en justicia, para evitar desórdenes.

Las resoluciones del Cabildo se determinan en virtud de un proceso de'iberatorio, seguido de votación. "Si el negocio en que hablaren disponen las Ordenanzas de Granada (3) fuere tal, que fea menester hablar en él primero, para mejor determinar lo que en él fe deua hazer, y para poder dar bien, y con acuerdo fus votos, puédenlo hazer, y cada vno por la orden fufo dicha en el cafo". Las de San Felipe (4) establecen concretamente que "en cualquiera classe de negocios, antes de resolverse, siendo graves, deberá conferirse, para que con mayor conocimiento se delibere... hablando cada uno por su orden... y si huviere variedad de dictámenes, mandará el Corregidor que fe vote".

Interesa ahora considerar en qué forma se producen esas votaciones y cuál es la intervención del Corregidor en las mismas, en el ejercicio de sus funciones presidenciales. Desde. luego se carecía en esta materia de un precepto de carácter general y eran las Ordenanzas de los municipios las que resolvían esta cuestión con distintos criterios: unas, exigiendo la conformidad de las dos terceras partes; otras, pidiendo solamente la mitad; y algunas, en fin, como se hace constar en las Cortes de Zamora de 1423, determinando "que todos han de ser concordes en lo que se oviese de facer". En dichas Cortes se pretendió que el Rey estableciese, con caráctr general, el

(1) Ordenanzas de San Phelipe, Libro Capitular de San Phelipe de 1752. Parte I, Ord. V.

(2) Idem; parte I, Ord. XVI.

(3) Ordenanzas de Granada, Título 2, Ord. II.

(4) Ordenanzas de San Phelipe, cit.; Parte I, Ord. XXIII. 
principio mayoritario, pero el Monarca se limitó a contestar que "se guarden las Ordenanzas que cada una Ciudad o Villa o Lugar cerca de esto tuvieran, i se guíen por ellas, i no las aviendo, o aviendo contrariedad en ellas, o diversidad, en tal caso se guarde lo que el derecho disponga... (1).

En realidad, los más remotos precedentes de la legislación de Castilla no aceptan la solución mayoritaria, y así puede observarse que la Ley X, Título XIV, de la Partida I, declara que "... si los quc; son pocos, dixessen cosa más convenible, y que sea más a pro de la Iglesia, aquélla deve valer, e no lo que dixeren los más..."; pero precisa reconocer que las Ordenanzas de muchas y muy importantes poblaciones resolvían las discrepancias entre los capitulares por el voto de la mayoría.

Veamos ahora cuál es la intervención del Corregidor en las votaciones. Normalmente no tiene voto (2), o se emplea la fórmula de que debe adherirse a la opinión de la mayoría (3); y en ese caso sólo tiene intervención en las votaciones cuando se produce un empate, para decidirlo con voto de calidad (4) De modo excepcional. en ciertos lugares, posee determinados privilegios, como ocurre en Sevilla, donde el voto del Asistente "vale tanto como el tercio de los capitulares que votan y un voto más; en tal forma que de 24 Regidores los 9 y el assistente, es mayor parte de votos, que el número de 15 que restan" (5).

B) Autorización de las reuniones capitulares.-Ya hemos visto que el Cabildo sólo puede actuar legalmente con la presencia del Corregidor, puesto que la justicia es "cabeça del Ayuntamiento, el fiel y el veedor principal del bien común".

C) Funciones ejecutivas.-Según Castillo de Bovadilla, el Concejo carece de jurisdicción y no puede llevar a la práctica sus pareceres y deliberaciones; " el executar los acuerdos del Regimiento

(1) Co'meiro. Manuel: "Cortes de los antiguos reinos de Leon y Castilla". Madrid, 1883. Tomo I. Págs. 656 y 657. Ley V, Título I. Libro Vir de la Recopilación.

(2) "En el Ayuntamiento y materias del Gobierno de la Repáblica, sólo tienen voto los Regidores..." Santayana Bustillo, ob. cit.; pág. 34 .

(3) "Y defpues que todos los Regidores ayan dado fus votos en el negocio que hablaren, la Iufticia ha de dar el fuyo. confirmándofe con la mayor parte de los Regidores..." Ordenanzas de Granada; Título 2, Ord. 14.

“... Que es costumbre en este Ayuntamiento, de tiempo inmemorial a esta parte, que si algán negocio se vota, lo que sale por mayor parte, los Caballeros Corregidores se conforman con ello, y asi lo juran y prometen el día que toman en éste Ayuntamiento posesion de sus oficios..." Libro de Acuerdos. del Ayuntamiento de Zamora. Sesión de 28 de diciembre de 1622 . Fernández Duro, (C.) "Memorias históricas de la cludad de Zamora, su provincla y Obispado". Madrid, 1882. Tomo II, pág. 559.

(4) El Corregidor no tiene voto en los negocios del Cabildo, fino en los cafos de igualdad, en los quales podrá arrimarfe a la parte que le parezca más conveniente y jufta, con lo cual avrá Acuerdo, y fe deverá executar'. Ordenanzas de San Phelipe, cit.; Parte I: Ord. XXVI.

"... No tienen voto los Corregidores sino habiendo igualdad, en cuyo caso el suyo es decisivo..." Ortiz de Zañiga (M.) y Herrera (C.): "Deberes y atribuciones de 108 Corregldores, Justicias y Ayuntamientos de España". Madrid, 1832. Tomo I, pág. 333 .

(5) Miravel y Casadevante (Joseph): "El gran Diccionario histórico". Paris, 1753. Tomo III, pág. 456. 
-dice ese autor-y mandar pregonar, imponiendo penas, o sin ellas, es acto que pertenece al mero y mixto imperio del Corregidor..." (1). Así lo establecen las Ordenanzas de San Felipe, preceptuando que corresponde a la Justicia, como facultad presidencial, "el mandar executar los Acuerdos; y quando fe aya de hacer algún Pregón en confequencia de lo acordado, se ha de poner en fu nombre..." (2).

II.-Lo indicado anteriormente determina la posición normal, estrictamente juridica, del Corregidor con respecto al Ayuntamiento. Ahora bien, existían un conjunto de preceptos y de prácticas, con fuerza de ley, que concedían a ese Magistrado, de un modo excepcional, la facultad de apartarse de la voluntad del Cabildo, expresada por la mayoría de sus capitulares, aceptando el criterio de los menos o aun imponiendo el suyo por encima del parecer contrario de todos los Regidores. Estas atribuciones, repetímos, debían ejercitarse a título de excepción; por regla general prevalecía el dictamen de la mayoría. Así dice Castillo de Bovadilla (3) que "el Corregidor siempre que pueda se conforme con la mayor parte de los Regidores, y sólo les contradiga en los negocios graves, en que no pueda excusarlo sin cargar su conciencia o faltar a su oficio".

No obstante, desde los orígenes de la institución ya observamos la facultad concedida al representante del Rey para imponerse a] Regimiento. El título de Asistente de Sevilla, a favor de Pedro Manrique, que lleva fecha de 6 de septiembre de 1461, dice así: "... vos mando a todos e cada uno de vos... hayades e recibades por mi Asistente desa dicha Cibdad al dicho Pedro Manrique, mi vasallo, e le dejedes e consintades estar e asistir en vuestros Cabildos e Ayuntamientos; e que todas las cosas que ende ficierdes e ordenardes, así en lo que toca a mi servicio como al buen regimiento desa Cibdad las fagades e ordenades de su acuerdo e consentimiento e non en otra manera" (4).

Los precedentes doctrinales reconocen, asimismo, desde los primeros tiempos, la autoridad dẻ la Justicia por encima de todas las resoluciones del Concejo. "... suele también acontescer-dice a este respecto Salgado Correa (5)-que los Regidores y Officiales que tienen voto en los Ayuntamientos y acuerdos de la gouernacion del pueblo, aunque sean de diversas opiniones y parcialidades, se suelen a vezes conformar y concertar en algunas cosas que les paresce que a ellos les conuiene o a sus preminencias, en general o en particular: las quales son en deseruicio del rey, y en daño de su pueblo, aunque las propongan con todo color y muestra de justicia y de razón, deue el juez estar auisado y auertido para no las consentir, y para impedírselas por los más justos, lícitos y honestos términos que pudiere: $y$ de tal manera, que no parezca que tiene en ello particular pretesión, impida que no se haga ni ordene lo que no

(1) Castillo de Bovadilla, ob. cit.; vol. II, págs. 142 y 143.

(2) Ordenanzias de San Phelipe, cit.; parte I, ord. V.

(3) Castillo de Bovadilla, ob. cit.; tomo II, pag. 160.

(4) Guichot y Parody, ob. cit.; tomo I, pág. 171.

(5) Salgado Correa: Libro nombrado Regimiento de Jueces, Sevilla. Capitulo XXTII. 
se deua hazer, vsando en ello de la auctoridad pública de su officio, con justicia y con razón...".

Castillo de Bovadilla sostiene un criterio análogo, afirmando que el Corregidor debe actuar "...no atándose ni ateniéndose siempre a los votos de la mayor parte, si no a los de mayor razón; y si el negocio que se acordare fuere tan notoriamente injusto, y contra el buen govierno, aunque todos vengan ello él sólo lo contradiga y autorve..." (1).

En la práctica encontraba plena aplicación esta doctrina de los jurisconsultos. Así, por ejemplo, en una empeñadísima controversia sostenida en Zamora entre el Corregidor de la ciudad y los Regidores sobre una petición de servicios interesada por Felipe IV, contra la cual se pronunciaron los capitulares, aquel Magistrado manifestó "que todo lo que los caballeros Rexidores de este Ayuntamiento han votado es derechamente contra lo que Su Magd. pide en su carta, y que estando aquí su md. en lugar de Su Magd. y representando su persona, no debe ni puede conformarse con los dichos votos..." (2). En Sevilla el Asistente encarcelaba y condenaba en 1638 por desobediencia a los miembros del Cabildo que se negaban a acordar, sobre la reunión de Cortes, de conformidad con lo interesado por el Rey (3). Con ello se precisa adecuadamente el fundamento de la doctrina que venimos exponiendo sobre las relaciones entre el Regimiento y el Corregidor, o sea la imposibilidad de que en el Estado absoluto, neta e integralmente totalitario, pudiera prevalecer interés particular $o$ voluntad de entidad subordinada frente a la autoridad del Rey, ante la cual debían inclinarse los particularismos locales de toda especie. En el Estado absoluto, como en el totalitario de nuestro tiempos, no caben autonomías de ninguna clase. Como dice Guichot (4), era el Corregidor desde 1478 "una autoridad activa, de grandes prerrogativas y fueros, que mermaron las inmunidades y franquicias de la municipalidad... y los privilegios y costumbres de la nobleza y daba. caracter de acción directa del Rey sobre el gobierno y la administración del pueblo...".

Incluso en territorios que, como los vascongados, constituyen una excepción en el sistema, pues el Corregidor no tiene en ellos carácter municipal ni interviene en el Cabildo; en países como en Vizcaya, de tan arraigado espíritu autonómico, que reaccionaba vivamente ante cualquier intromisión del poder central, y en que el Corregidor ejercía de derecho simples funciones presidenciales en la Junta del Señorío, se ve obligado.Sagarmínaga a reconocer que "ésta manera de de'iberar, en concurrencia con el Corregidor, que era representante' de la Corona, recuerda la costumbre que se seguía en los ordenamientos de las Cortes de Castilla, en donde los decretos venían a ser peticiones que el Rey concedía o denegaba"; Areitio añade que ello era

(1) Castillo de Bovadilla, ob. cit.; tomo II, pág. 159.

(2) Sesión del Ayuntamiento de 28 de diciembre de 1622. Fernández Duro (Cesáreo): "Memorias históricas de la cludad de Zamora, su provincia y Obispado". Madrid, 1882. Tomo II, pág. 569.

366 (3) Guichot y Parody, ob. cit.; tomo II, pág. 239.

(4) Guichot y Parody, ob. cit.; tomo II, pág. 345. 
cosa bastante frecuente (1), y hay que reconocer que, en realidad, la postura del Rey ante las Cortes ofrecía bastante analogía con la del Corregidor frente al Regimiento.

Ahora bien, la justificación legal de la realidad imperante no es muy clara. El mismo Castillo de Bovadilla experimenta dudas muy vehementes sobre la solidez jurídica de la doctrina que establece, fundándola tan sólo en un inciso de la petición 47 de las Cortes de Zamora de.1432, a la que ya hemos hecho referencia, en la cual se establece que cuando las Ordenanzas locales no regulasen las votaciones "o avido contrariedad en ellas, o adversidad, en tal caso se guarde lo que el derecho dispone", entendiendo que esto se refiere a la Ley X, Título XIV de la Partida I, que ya hemos citado con anterioridad, la cual dispone que debe prevalecer la opinión de los menos cuando es la mảs acertada (2).

Ello es bien vago e impreciso, pero puede comprobarse además la existencia de otros preceptos más concretos, que Castillo no recoge en su obra. Guardiola afirma, a este respecto, que podrá el Corregidor rrivar de eficacia las resoluciones de los Ayuntamientos en lo acordado por la mayor parte cuando sea opuesto "al servicio de Dioz y del Rey o bien común del pueblo", haciendo constar que así lo determina el Capítulo XLIII de una Instrucción de 1749 (3). Por otra parte, el Capítulo XLIII de la Instrucción de 1713 para Aragón y Valencia (4) coincide exactamente con la indicada disposición. Dice así: "Que el Corregidor no embarace las resoluciones de los Ayuntamientos en lo acordado por la mayor parte sino en el caso de ser opuestas al servieio de Dios y del Rey o bien universal del pueblo, en cuyo caso lo pueda hacer".

III.-Resultaba de todo esto, que si bien el representante del Rey debía en principio someterse a la voluntad de la mayoría del Regimiento, se le concedía en la práctica una amplísima libertad para proceder con arreglo a la suprema conveniencia del Estado y del interés público. De todos modos, la ficción subsistía, y la postura del Corregidor debía adoptar, en muchas ocasiones, apariencias de arbitrariedad, colocándose frente a la totalidad de los miembros del Concejo para servir los intereses generales. Por ello, fué preciso que la legalidad vigente reconoeiese, desde los primeros tiempos, esta situación anormal y diese cauce jurídico y carácter ejecutivo y permanente a situaciones al margen de la Ley, a las que se veían obligados a desembocar los Corregidores con mucha frecuencia, constreñidos por el sistema imperante de respeto a las exterioridades tradicio-

(1) Sagarmínaga (Fidel de).-El Goblerno y Régimen foral del Señorío de Vizcaya. Nueva edición ampliada por Darío Areitio. Bilbao, 1832. Tomo II, pág. 58 .

(2) Castillo de Bovadilla, ob. cit.; tomo II, pág. 159.

(3) Guardiola (Lorenzo): "El Corregidor perfecto y Juez exactamente dotado de las calidades necesarias y convenientes para el buen gobierno económico y político de los pueblos". Madrid, 1785. Parte 3.4, citando a Martínez.-Librería de Jueces. Tomo JII, fol. 49 y siguientes.

(4) Capitulos que han de guardar los Corregidores en el exercicio de sus opcios, por lo respectivo a Arago.. $\because$ 'ra!excia. Ijibro Cápitular de Sán Phelipe correspondiente a 1327 . 
nales de la autonomía concejil, cuando no podían evitar la violencia con fórmulas dictadas por el tacto y la habilidad del funcionario (1).

Estas modalidades de actuación del Corregidor en el seno de los Regimientos, en cierto modo y medida al margen de la legalidad, se enderezaban en diversas direcciones, que es conveniente analizar. En primer lugar, debe tenerse en cuenta que, en virtud de un complejo de circunstancias de carácter psicológico, más bien que estrictamente legales, la personalidad del Corregidor, por el mero prestigio del cargo, ejercía una influencia predominante, decisiva, en la marcha del municipio, sin necesidad de apelar a procedimientos de tipo coactivo. Así se desprende de la literatura de la época. El Conde de Floridablanca (2), refiriéndose a estos Magistrados, pone en boca de Carlos III en la instrucción reservada para la Junta de Estado, que "de ellos depende casi toda la felicidad de mis vasallos; si los Corregidores son justos, desinteresados, hábiles, prudentes y activos, todos los ramos de justicia y policía se manejarán bien". Por otra parte, basta la simple lectura de los Libros Capitulares de la época, para observar que en la marcha normal de los asuntos imprime la voluntad del Corregidor una acusada orientación, a la que se pliegan generalmente los criterios particulares de los Regidores; pudiendo comprobarse que parte de él la iniciativa de todos los asuntos de importancia.

Su carácter de representante del Rey le concede un prestigio y - una autoridad verdaderamente extraordinarios, en los cuales entraba indudablemente el respeto, pero en los que tampoco era extraño el temor, pues no debe olvidarse que a sus atribuciones jurisdiccionales se unen las de encargado de la policía de seguridad y del orden público, con facultades excepcionales que crean en torno suyo una aureola de extraordinario poder.

(1) Dice la Pragmática de 26 de jullo de 1502 (Ley LIV, título V, 11bro II de la Recopllacion): "Porque somos informados que muchas veces se siguen muchos inconvenientes de rescibir nuestro Presidente y Oldores todas las apelaciones indistintamente y mandar sobreseer en la execución. mayormente en las cosas que se mandan en las ciudades, villas y lugares cerca de la gobernación dellas... porqué por esto se impide la buena gobernación de las dichas cludades, villas y lugares y es muchó perjuicio para las comunidades y causa de muchos gastos; y por la mayor parte de la execución de estas cosas es de menos perfuicio a las partes que dello se agravian: ordenamos e mandamos que cuando semejantes causas vinieren a la nuestra Audiencia... que antes que los nuestros Presidentes y Oidores sobre ello provean, lo miren mucho; $y$ que antes de inhibirse o mandar sobreseer, manden a los dichos los nuestros Corregidores $y$ otros Officiales de las tales ciudades, villas y lugares, que envien la razón dello ante ellos, y la causa que les movio a hacer lo que hicieron y mandaron; y después de ser informados dellos, y oidas las partes, provean los que les pareclere justo, habiendo congideración al bien páblico; ca cuando las cosas de esta calidad son de poco perjuicio, siempre se debe mucho mirar do que paresciere que conviene al bien coman".

(2) Floridablanca (Conde de). Instrucción reservada que la Junta de Estado creada formalmente por Mi Decreto de este día 8 de julio de 1783 deberá observar en todos los puntos y ramos encargados a su conocimiento y examen. XLVII. Dbras originales. Biblioteca de autores españoles de Rivadeneyra. Tomo 58. Madrid. 1867. 
Es, además, evidente que su preparación jurídica había de concederle una influencia trascendental en una Corporación generalmente iletrada. "Los presidentes-de los Regimientos-, dicen Ortiz de Zúñiga y Herrera (1), con especialidad siendo letrados, tienen a su cargo, en todos los actos consistoriales, la ilustración de los puntos de derecho que ocurran, porque son o deben ser, si puede asi decirse, el timón de los Ayuntamientos."

Por otra parte, la autoridad y el ascendiente a que nos venimos refiriendo y la práctica adquirida en los negocios, le permitía al Corregidor orientar las decisiones y ejercer una función arbitral y pacificadora en las disensiones de los capitulares. "Fi en algo vuiere difcordia, y la Iufticia quifiere platicar en el Regimiento, por alguna cofa-dicen sobre este particular las ordenanzas de Granada (2) que lo pueda hazer hafta que fe tenga orden, que fe concierte en 10 mas cierto y prouechofo, defechando toda afición, como buen Juez".

Podía también el Magistrado a que nos venimos refiriendo utilizar determinadas fórmulas dilatorias como medio de oponerse a las resoluciones concejiles que estimase inconvenientes. Para ello, ejercitando sus facultades presidenciales, le era dado ocasionar demoras en el trámite de los negocios, que prácticamente equivalían a un aplazamiento sine die. Así, por ejemplo, una Ordenanza de las de San Felipe (3) dispone que "si entendiere el Corregidor que en algunos negocios de los que ocurren o se proponen.... se quisiere passar a votar con fin particular, que pueda traer perjuicio en la resolución... suspenderá la deliberación...". Y como, además, era atribución exclusiva del mismo, como ya hemos visto, la ejecución de los acuerdos adoptados por las Corporaciones municipales, ello equivalía prácticamente a una competencia ilimitada para la suspensión de los mismos, y así ocurría en realidad. Las repetidas Ordenanzas de San Felipe establecen así esta facultad suspensiva de alcance indefinido: "Cuando los capitulares acuerden de conformidad, o por mayor parte, alguna resolución que sea notoriamente contraria a Justicia, contra las Leyes, Reales Ordenes, Ordenanzas, o contra el bien común, mandará el Corregidor se suspenda su execución, previniendo al Procurador general tome la voz, si se instase recurso de la providencia de suspensión..." (4).

IV.-Para encontrar la fórmula justa de la intervención del Corregidor en la administración del municipio, precisa efectuar un examen a fondo de las diversas materias atribuídas a la competencia del Ayuntamiento y del modo en que se efectúa, realmente, el gobierno de la ciudad.

La primera observación que nos sugiere el examen de la dinámica municipal es la de la función prácticamente restringida de las Corporaciones, que se limitan, en suma, a fijar directrices generales

(1) Ortiz de Zuñiga y Herrera, ob. cit.; tomo I, pág. 338.

(2) Ordenanzas de Granada Título 2, Or. II.

(3) Ordenanzas de San Phelipe, cit. parte I, Ord. XXV!1I

(4) Ordenanzas de San Phelipe, cit. parte I, Ord. XXX. 
b a resolver los asuntos de importancia. El detalle de la administración queda a cargo de comisiones reducidas, que salen del seno del Concejo, con delegaciones permanentes y específicas y que actúan con plenitud de atribuciones, no con carácter meramente informativo, como en el municipio actual, sino plenamente resolutorio, dentro de los límites que les fijan los acuerdos del Aydantamiento y las Ordenanzas municipales (1). Es una supervivencia del polisinodismo característico en toda vieja administración española.

Estas comisiones estaban constituíalas, las más de las veces, por dos o cuatro Regidores, con la denominación de Diputados, que st nombraban cada año, generalmente por sorteo (2). Cada una de ellas tenían a su cargo un determinado ramo de la administración.

Ahora bien, de todas estas comisiones formaba parte la Justicia como presidente nato, y es evidente que su actuación en las mismas era decisiva. Así, por ejemplo, en las Ordenanzas de Granada se exige para cualquier obra en las conducciones y tomas de agua la licencia de la Justicia, de uno de los Alcaldes y del Administrador, conjuntamente (3) ; y refiriéndose a los Diputados de rentas, determinan dichas Ordenanzas concretamente el mecanismo de las comisiones citadas, estableciendo "que cuando las dichas perfonas que fueran deputadas no estuvieren todas conforme en alguna cofa, que fe haga como pareciere a la mayor parte, con tanto, que aya en ellos la Iufticia y un Ventiquatro, o que lo confulten con la Ciudad fi de efta manera no fe concertare" (4).

Esta actuación preponderante del Corregiōor en las comisiones entregaba prácticamente al mismo un número ilimitado de asuntos municipales, que de ese modo quedaban sustraídos al conocimiento del Cabildo. Porque, como hemos dicho, esas Diputaciones no actuaban en una esfera estrictamente informativa, preparatoria o de ejecución de las resoluciones del Regimiento. La lectura de Ordenanzas y Libros Capitulares nos hace ver que poseían atribuciones resolutorias y que reemplazaban al Cabildo en todos los asuntos de detalle y de menor importancia y aún en muchos que la tenían trascendental. Así, por ejemplo, con respecto a los citados Diputados de rentas, junto con la Justicia, determinan las Ordenanzas de Granada (5) que "fe entienda que tienen poder para recebir las pofturas, $\mathbf{y}$ otorgar prometidos, $\mathbf{y}$ hazer los remates, y todas lás otras cofas que conuiene, y tocaren el hazer arrendar las Rentas de los Propios...". Estas comisiones llegaron a dictar, en las materias de su

(1) En Cabildo celebrado en Sevilla en 20 de marzo de 1554 se acordó designar Diputados de Policía Urbana "y que estos tuviesen facultades bastantes para todo lo concerniente a este negocio y para hacer cumplir los acuerdos del Cabildo". Guichot y Parody, ob. cit.; tomo II, págs. 37 y 38 .

(2) Ordenanzas de San Phelipe, cit. Parte I, título II, ord. I.

(3) Ordenanzas de Granada; título 106, 107 y 108.

(4) 1 dem. Tit. 4, ord. 5.

(5) Idem. Tit. 4, ord. 2. 
competencia, verdaderas Ordenanzas y resoluciones de carácter general (1).

V.-Constituye un verdadero tópico en la literatura de la época y entre los histor̂iadorès de nuestro tiempo la afirmación de la universalidad de la competencia del Corregidor. Así lo hemos hecho constar anteriormente, y añadiremos ahora que la lectura de la Instrucción de 1788 y de otras disposiciones da la intípresión de que no existe materia alguna que le esté vedada. Ahora bien, si atendemos a las diversas Ordenanzas municipales, se observará que los Regimientos recaban también para sí el conocimiento de un número tal de asuntos que equivale realmente a una competencia, por lo menos tan amplia como la concedida al Corregidor.

Esta competencia, tal como la plantean las Ordenanzas concejiles y la propia legislación, alcanza proporciones verdaderamente extraordinarias. "Administraban las rentas de propios-dice Fernández Duro (2) -, disponiendo además las generales, repartimientos, sisas, pontazgos, con cuyo producto atendían a las obras públicas de la ciudad y a las de primera necesidad en la tierra, como puentes y calzadas, y al servicio del reino, según lo votado en las Cortes. En el ramo que hoy llamamos de Fomento, atendían con interés a la repoblación del arbolado, a la conservación de la caza y la pesca, a la cría caballar y al auxilio de los labradores en plagas y calamidades, señaladamente en la de langosta, que se repitió varios años. En el de Instrucción pública no tenían gran cosa que hacer, toda vez que no había en la ciudad-en Zamora-más que una cátedra, en que se leía gramática... En beneficencia sostenían los hospitales de fundación particular, la alhóndiga del pan, y el Médico y el Cirıjano titulares, fomentando en cambio en Industria la muy importante de paños y mantas, las de curtidos, lienzos, encajes, cerrajería, sedas, harinas, para todas las cuales habían hecho sabias ordenanzas y traído, en particular de alguna, maestros de Flandes. En punto a milicia, levantaban compañías siempre que eran menester con las prerrogativas de elegir y nombrar los capitanes..." Y a esta gráfica descripción del contenido de la administración municipal de Zamora durante el reinado de Carlos I, habremos de añadir que en todo el período de la monarquía absoluta, la indicada esfera de acción del Regimiento se completaba, según las diversas Ordenanzas, con todo lo referente a las cuestiones de abastos, que eran quizá el problema más importante de los atribuídos a la administración de los municipios, y las de policía urbana y rural.

(1) "Mandan los Señores, Iufticia y Diputados... que ningan panadero... ni vezino... fean de fallr a los caminos, ni a las callas a tomar el pan, trigo, ceuada, que fe viene a vender a efta Ciudad". Ordenanzas de Granada, cit., t1tulo 5, ord. 35. "Mandan los feñores Iufticia, y Diputados..., que ningan menudero, ni moço del, fea offado de abrir ningún carnero, ni cortar ninguna cabeça de carnero, ni de baca, ni de otra res... en el Matadero defta Ciudad". Idem. Tít. 13, ord. 65. "Los señores de Iufticia y Diputados.. madaron que de aqui adelante todos los tundidores... no fean offados de poner tieda fin - primero de fianças baftantes... Idem. Tít. 64, cit.; tomo III, págs. 463 y 464.

(2) Fernández Duro, ob. cit.; tomo III; págs. 463 y 464. 
Era ello una situación bien singular y característica, con todas las apariencias de una duplicidad de funciones. Existe, sin duda alguna, una dualidad de competencia en materia municipal. Su peculiar legislación confía al Corregidor, como hemos visto, un número verdaderamente copioso de materias que las Ordenanzas y las prácticas consuetudinarias atribuían a la vez al Regimiento. Hay más todavía. Muchas disposiciones atribuyen un mismo asunto, simultáneamente, a la Justicia y a los Regidores, sin pararse a determinar en qué forma ha de resolverse en la práctica este confusionismo. Así, por ejemplo, los repartimientos y derramas para gastos que no se cubrían con la renta de Propios no podían efectuarse, según la petición de las Cortes de Zamora de 1432 (1), "sin ser a ello presentes y consencientes las Justicia y los Regidores"; la petición 38 de las Cortes de Valladolid de 1537 (2) hace constar que "cuando algunas condenaciones se hacen por los Corregidores e Justicias de nuestros reinos de penas aplicadas para algunas obras públicas, mandamos que lo tal se gaste y distribuya interviniendo en ello el Regimiento de la Ciudad o Villa donde se hiciere la tal aplicación, porque se sepa cớmo y en qué se gasten las tales penas"; el capítulo XVII de la Pragmática de 1500 ordenaba a los Corregidores que "...si vieren que algunas Ordenanzas se deben deshacer y enmendar, las harán de nuevo con acuerdo del Regimiento"; una Ordenanza de 1487 (3) determina que "las Justicias y Concejos que fagan abrir y adobar los carriles y caminos por do pasa y suelen pasar y andar las carretas y carros..."; el capítulo VI de la Pragmática de 15 de mayo de 1584 (4), regulando la administración de Pósitos, establecía "que el repartimiento y gasto de dicho pan-lo hagan-la Justicia y Regimiento, pudiéndose buenamente juntar, y donde no, la Justicia y dos Regidores por lo menos, que para ello serán nombrados, a cuyo cargo ha de ser esto, y no de otro ninguno..."; pudiéndose repetir estas citas.

Precisa, pues, reconocer la existencia de una modalidad peculiarísima de gobierno municipal, determinada por la actuación conjunta de dos.elementos distintos-el Corregidor y los Regidores-, que aunque reunidos en el seno del Cabildo, permanecen en el mismo sin confundirse, conservando sus respectivas personalidades, con atribuciones en ocasiones no bien diferenciadas y siempre paralelas, cuyo equilibrio se logra mediante una colaboración que la ley no regula expresamente, pero que las prácticas usuales habían elevado a sistema normal.

De todo lo que llevamos expuesto en el presente capítulo y en los anteriores podemos llegar a la conclusión de que el régimen municipal de la monarquía absoluta, aún conservando las apariencias de la época concejil, se basaba, realmente, en una coadministración del

(1) Ley II, titulo VI, libro VII de la Recopllación.

(2) Ley II, titulo XXXIV, Jibro VII de la Recopilacion.

(3) Ley II, título XXXV, libro VII de la Novisima Recopilacion.

(4) Ley I, título XX, libro VII de la Novisima Recopilación. 
Corregidor y de los miembros perpetuos del Regimiento, en la cual, si bien es evidente que alcanzaba franco predominio el representante del Rey, no es menos cierto que ello había de lograrse como consecuencia de un proceso más o menos dilatado y complejo, en el que la opinión de los Regidores podía imprimir una acusada orientación a las resoluciones consistoriales y aun, las más de las veces, era esa opinión la que normalmente prevalecía.

No será improbable que la etimología vulgarmente aceptada de la palabra Corregidor (1) acuse un error de enfoque al fijar como fundamental entre las atribuciones de ese Magistrado la de "corregir" las anormalidades jurídicas en el territoric en que actuaba. Quizás no fuera disparatado suponer que el propósito de la monar. quía, al establecer la institución, fué simplemente el de llevar un Regidor más al seno del Concejo, que en colaboración con los otros y sin alterar las exterioridades tradicionales del municipio medieval, pudiera encuadrar las actuaciones del mismo dentro de las normas de absoluto predominio estatal que son fundamento básico de la monarquía absoluta. Lo evidente es que los primitivos jueces de salario, de facultades estrictamente jurisdiccionales, no reciben esa denominación, que sólo se utiliza cuando a la Justicia real se la admite en los Concejos municipales; y no hay que olvidar tampoco que el nombre de Asistente que se da desde los primeros tiempos a los Corregidores de ciertos municipios, entraña un sentido de colaboración concejil, muy de acuerdo con este criterio nuestro.

Nos encontramos, pues, ante un "co-regidor", en que la partícula afija tendría simplemente la estricta significación gramatical de unión o compañia, quedando establecido el sistema de co-administración que se refleja en toda la legislación y en las prácticas de la época y cuyas características fundamentales podemos sintetizar así, como consecuencia del estudio efectuado:

1. Se mantienen las exterioridades tradicionales y, teóricamente, es la mayoría de votos, en el Regimiento, la que determina el gobierno municipal.

2. En una postura casi extrajurídica, y en virtud de prácticas consuetudinarias y de su autoridad como representante del poder real, el Corregidor ejerce acción preponderante en la formación y ejecutoriedad de los acuerdos municipales, cuya acción se determina del siguiente modo:

a) Mediante una función orientadora y de dirección e impulso muy acentuada.

b) Por la posibilidad excepcional de imprimir a un asunto determinado un criterio distinto al de los Regidores.

c) Por la facultad de suspender los acuerdos del Regimiento.

$3 .^{\circ} \quad$ La actuación normal del Corregidor, en la administración del municipio, de acuerdo con las reglas jurídicas establecidas, se perfila en las siguientes trayectorias:

(1) Colmeiro estima que dicha denominacion fue originariamente "quad eorrectores", de Ja constitucion, etc. Cit.; tomo II, pag. 208. 
a) Funciones presidenciales y ejecutivas.

b) Actuación preponderante en las Comisiones municipales.

c) Una vasta zona confusa de competencia, esencialmente municipal, que se le atribuye al representante del rey por diversas disposiciones en materias que, por otra parte, están también confiadas al conocimiento de los Regidores.

d) Intervención del Corregidor, en vía jurisdiccional, en las resoluciones del Concejo.

Así, pues, la dinámica normal del sistema es la de una administración puramente concejil, en la que el Corregidor se limita a ejercer funciones presidenciales. En ella, mediante una prudente acción orientadora, logra imprimir las directrices que estima pertinentes a la marcha del municipio, no haciendo uso de sus facultades excepcionales más que en contados casos de gran importancia, cuando se ve obligado a ello por sugerencias derivadas de las altas esferas del gobierno del país o cuando circunstancias extraordinarias lo exigen. En lo demás procede con habilidosa cautela en lo que a su actividad concejil se refiere. Castillo de Bovadilia dedica todo el capítulo VII del libro III de su obra a exponer un conjunto de reglas para lo que denomina "lidiar con los Ayuntamientos", que considera la más difícil tarea del cargo, en la que deberán proceder" "usando de industria y destreza... para encaminar algún negocio del servicio del Rey, cuyo buen fin desea dirigir el Corregidor". Ello, como ya hemos dicho, lo resumía afirmando que "el Corregidor siempre que pueda se conforme con la mayor parte de los Regidores, y sólo les contradiga en los negocios graves, en que no puede excusarlo sin cargar su conciencia o faltar a su oficio".

Desdevises du Dezert (1), examinando las características del régimen español del siglo XVIII, destacaba la aparente incongruencia de que no subsistiera en el gobierno local el sistema de asambleas consultivas que caracterizaba acentuadamente al gobierno central, y que según él era sustituído, en las administraciones periféricas, por un jefe único que asumía todos los poderes. La observación no es exacta. Ocurre precisamente todo lo contrario, es decir, que desde la cúspide de la jerarquía nacional hasta las últimas ramificaciones de la misma, se mantiene un sistema uniforme de los diversos grados, que se caracteriza por la actuación de dos diversos órganos paralelos: el Jefe, en que se individualiza toda la potestad de mando, y el Consejo asesor; acumulándose en estos organismos, sin distinción alguna, las funciones administrativas y jurisdiccionales con las de gobierno político. $\mathrm{Y}$ así nos encontramos en lo más alto al Rey y sus Consejos; en las provincias al Virrey o al Capitán General, con la Chancillería o Audiencia, y en el último peldaño, a los Corregidores, con los respectivos Concejos municipales.

No hay que perder de vista, sin embargo, que la función asesora en la administración española de la época que estudiamos está bien

(1) Desdevises du Deze: "L'Espagne de l'Ancien Régimen". París, 1889.

374 Tomo II, pág. 122. 
apartada del criterio estático en que se inspira, en este particular, el municipio totalitario de nuestros tiempos. No puede decirse, por ejemplo, que el Consejo de Castilla posea atribuciones propias, que sea un cuerpo activo de la administración; la potestad de mando radica en el Rey exclusivamente, y las actuaciones de aquella asamblea tendrán validez solamente en tanto se supongan emanadas de la voluntad real y mientras no se hallen en oposición con la misma; es decir, que el Consejo es simplemente un organismo asesor y auxiliar; $y$, sin embargo, en la práctica dista mucho de ser un órgano pasivo, y se le ve resolver y obrar por sí mismo, como si poseyese una competencia privativa. Es un procedimiento particularísimo, que pudiéramos denominar "asesoramiento activo".

Algo semejante ocurre en los organismos municipales. En realidad de verdad, cualesquiera que sean las exterioridades del sistema, las facultades resolutorias son poseídas fundamentalmente por el Corregidor, que es quien dice la última palabra y el único que puede conceder ejecutoriedad a los acuerdos del Regimiento. En el municipio no existe más potestad de mando que la que emana de la voluntad real. El Ayuntamiento, en realidad, formula los deseos y las necesidades de la República, que solo alcanzarán virtualidad en cuanto no discrepen de aquella voluntad estatal, manifestada expresa o tácitamente por el representante del Rey, y por ello afirma Castillo de Bovadilla que "...el parecer se ha de dar por los Regidores y la determinación se ha de tomar por el Corregidor..." (1), añadiendo, además, que "el Ayuntamiento... no tiene poder ni autoridad de mandar, ni determinar, ni poner en execución sus pareceres y deliberaciones, sino que se ha de referir en éstos a los Corregidores..." (2).

Por eso Sacristán Martínez (3) reconoce que los Concejos "quedaban reducidos a la categoría de Cuerpos consultivos"; pero estos criterios no deben inducirnos al error de asimilar al Ayuntamiento del período absoluto a la Consulta del actual municipio italiano, mero colaborador pasivo y subordinado del Podestá. El Consejo municipal de aquella época desarrollaba una función asesora bien particular; activa, operante; es éste un asesoramiento que normalmente crea actos jurídicos firmes y definitivos, mientras. los mismos coincidan con la voluntad estatal, personificada en el Monarca y representada por e! Corregidor.

Fernando Albi

Sicretario del Ayuntamiento de Bilbao.

(1) Castillo de Bovadilla, ob. cit.; tomo II, pág. 159.

(2) Castillo de Bovadilla, ob. cit.; tomo II, pág. 142.

(3) Sacristán Martínez: "Municipalidades de León y Castilla". Madrid 1877. Pág. 440. 